\title{
MOTIVATION FOR INDIVIDUALS' INVOLVEMENT WITH FAN PAGES
}

\author{
Willy Abdillah \\ Faculty of Economics and Business, Universitas Bengkulu \\ (cinoek29@gmail.com)
}

\begin{abstract}
This research examines the empirical model of individuals' involvement with fan pages. The research model was developed based on the social influence factors and the brand post popularity model. The research employed an online survey questionnaire. 300 samples were collected by using a purposive sampling technique, and analyzed using the Partial Least Square (PLS) method. The results showed that identification, interactivity, informational content and valence of comment were the motivating factors for the intent to become involved with fan pages. It was indicated that the brand popularity model was not the only relevant model to explain the social computing phenomenon in the context of fan pages, but social influence factors also play a part. The implications for stakeholders and further research are discussed.
\end{abstract}

Keywords: Social influence factors, brand post popularity factors, intention, and involvement with fan pages.

\section{INTRODUCTION}

This research was motivated by the emergence of various types of Social Networking Sites (SNS) that influence the behavior of an individual's involvement with them, and the way organizations and individuals use online marketing practices, such as Facebook's fan pages. Although a prior study did examine the motivation for individuals' involvement with fan pages using the online brand popularity model (DeVries et al., 2012), but it had its limitations, because it only examined fan pages' characteristics as the motivator for becoming involved. Meanwhile, the real reasons for an individual's motivation have not been studied by previous research. This raises the opportunity to re-examine the individual's motivation to become involved with fan pages by completing and combining the online brand popularity model (fan pages' characteristics) and the social influence factors of an individual's motivation to involve him or herself with online social media (Abdillah et al., 2012).

Within a few years, SNS became quite popular, such as Facebook which claims, in 2011, to have more than 800 million active members, since its establishment in 2004 (www.facebook.com). SNS can be described as social networking for social or professional interactions (Trusov, Bodapati, and Bucklin, 2009). SNS members can become friends with other members, but they can also become fans of a brand on a particular fan page.

Conceptually, fan pages reflect the customers' relationship with the brand (McAlexander et al., 2002), expand the brandcustomer relationship (Muniz Jr. and O'Guinn, 2001), and provide resources and social benefits to members (Bagozzi and Dholakia, 2006). Through fan pages, companies post brand related anecdotes, photos, videos, or other material. Then, fans of the brand can interact with the brand by liking or commenting on them.

In 2011, more than 50 percent of social media users follow brands on social media and more companies were investing in social media, as indicated by worldwide marketing spending on SNS reaching \$43 million (Williamson, 2011). Managers invested in social media sites to build relationships and interact with their customers. One way to achieve this goal was to create a brand community in the form of a fan 
page at a SNS, at which customers could interact with the company by giving likes and comments to the brand posted (Muniz Jr. et al., 2001). Fan page consumers of these brands tend to remain loyal and committed to the company, and more open to receiving information about the brand (Bagozzi et al., 2006). In addition, fans of the brand were more likely to visit the store, generate more positive Word-Of-Mouth (WOM) advertising, and be more emotionally attached to the brand than non-fans of the brand (Bagozzi et al., 2006). Thus, in general, the presence of SNS has changed the socio-economic patterns of human interaction and fan pages have changed the way companies communicate with their customers. This dynamic encourages research into fan pages in the marketing domain.

Although previous studies found social media marketing activities had successes, relatively little work was done into the factors that affected the popularity of the brand, as measured by the number of likes and comments posted on fan pages (Zabin, 2009). Studies of the brands' posts and popularity have not provided sufficient theoretical foundations and empirical examinations to explain the popularity of the brands. For example, previous studies indicated that the companies should experiment with different characteristics of the brand post, such as video, images, text, or questions (Keath et al., 2011). This situation provides an opportunity to conduct similar research.

The purpose of this study is to examine the individual's motivation to involve him or herself with fan pages. This study considers the characteristics of fan pages (for example, interactivity), their content (eg, information), and the valence comments that are replicated and adapted from research by De Vries et al. (2012). The third variables are used because they are the key variables that drive the individual's involvement with fan pages from the perspective of the online brands' popularity concept. However, the limitations of these variables (De Vries et al., 2012), in explaining the behavior of an individual's involvement with fan pages raises the opportunity to re-examine them. In addition, this study also considers the aspect of the user's motivation, namely if the internalization and identifi- cation can be replicated, as adapted from research by Abdillah et al. (2012). By integrating aspects of the fan pages' characteristics and the content and valence of comments with the user's motivational aspects, it is expected that this research model may comprehensively explain the reasons for an individual's involvement with fan pages.

This study differs from previous empirical studies conducted by De Vries et al. (2012) and Abdillah et al. (2012), because this study integrates two perspectives, social computing (theory of social influence) and social media marketing (brand popularity). This integration is expected to enrich the theoretical study of online marketing through the development of behavioral models for individuals' involvement with fan pages. It also contributes to developing research instruments that can be replicated by further similar studies. Practically, this study provides a scientific explanation for stakeholders. For corporations, particularly online marketers, this study presents an explanation of the implications of managerial behavior for an individual's involvement with fan pages, which will give strategic information to marketers about the ways to effectively build an online brand's popularity through its fan pages. Also, this study can be the basis for an analysis of business policies, in anticipation of changes in the pattern of society's socio-economic dynamics, as a result of the changes in the behavior of online marketing by the organizations and changes in the market's preferences that must be addressed by the company.

\section{LITERATURE REVIEW AND HYPOTHESES DEVELOPMENT}

This section describes the theories and concepts used to develop the research models and hypotheses. The theories used in this study were the social influence theory and the concept of individuals' involvement with fan pages.

\section{Individuals' Involvement with Fan Pages}

SNS are natural technology platforms for marketing because they provide access to a large number of users, who can be categorized based 
on their non-geographical communities, and the structured set of social relationships among admirers of the brand in the form of fan pages (Muniz Jr. and O'Guinn, 2001). Fan pages are an effective tool for increasing sales (Bagozzi et al., 2006). Fan pages also have the potential to improve the relationship between consumers and brands, and may affect members' perceptions and actions (Muniz Jr. and O'Guinn, 2001).

Fan pages facilitate interaction through the exchange of opinions about brands or specific products among their consumers, thereby involving the members in a form of WOM communication (McAlexander et al., 2002). WOM has been found to be a powerful tool for marketing, and has been used by individuals as a source of brand or product information (Buttle, 1998). Therefore, fan pages play an important role in enhancing commitment to the brand, and in making decisions to purchase it (Godes and Mayzlin, 2004).

Fan pages can be defined as the means by which the involvement of consumers' intrinsic motivation to interact and cooperate with community members, both in a cognitive and emotional involvement form, or as the result of encouragement, finds release (Van Doorn et al., 2010). Previous studies focused on the achievements of fan pages marketing objectives in increasing profitability (Hallowell, 1996). A recent study conducted by De Vries et al. (2012) focused on the antecedents of online brands' popularity, which was displayed by brand pages. Although previous studies have examined individuals' involvement with SNS from a variety of viewpoints, but studies specifically aimed at the context of fan pages are relatively limited. By integrating the research model of online brands' popularity (interactivity, informational content, and valence comments) by De Vries et al. (2012) and the social influence factors (internalization and identification) by Abdillah et al. (2012), this study re-examined the antecedents of individuals' involvement with fan pages.

\section{Social Influence Theory}

Kelman (1953) revealed in his concept of social influence that the persuasive communication theme is called the social influence theory. Kelman's theoretical research focus was into social influences and attitude changes, with emphasis on the differences among the influence processes, the relationship between the action and changed attitudes, and the concept of personal responsibility for acts committed in order to fulfill official authority. The social influence theory explains that social influence occurs when the thoughts or actions of individuals were influenced, consciously or unconsciously, by others as a result of changing the way a person perceives him or herself in a relationship with influencers, or other persons and the community at large.

Kelman (1961) divided the social influence processes into three main forms, namely compliant, internalization and identification. Compliant explains the situation when individuals accept social influences or avoid punishments (mandatory). Individuals who receive compliant social influences are seen as agreeing with the majority, even though they may refute this internally. But, this study excluded compliant because it was not a strong predictor of an individual's motivation to become involved with fan pages on online social media or social networking sites (Abdillah et al., 2012). Identification explains the situation when individuals receive social influences because of their interest in respected or admired sources of social influence (agents), such as celebrities or respected family members. Internalization describes the situation when individuals receive social influences because their content is congruent with the individuals' value systems. Individuals who receive internalization will receive social influences in general (public conformity) or private (private acceptance).

The application of the social influence theory in the study of online communities grew rapidly when empirical studies by Bagozzi and Dholakia (2006) confirmed the role of social factors in influencing social computing behavior. Those studies were not only conducted in the context of online communities, but also in the context of online marketing, particularly online brand communities (Bagozzi and Dholakia, 2002). Those studies not only confirmed the role of social influence factors but also found a new construct, namely the we-intention. The follow- 
ing discussion is about the development of the hypotheses for each variable to be examined in this study.

2.1. Brand Post Popularity Factors as the Determinant of Individual Involvement with Fan Pages

Social networking sites can be described as networks of friends for social or professional interactions. Members of social networking sites can become friends with other members, but they can also become fans of brands on dedicated brand fan pages. Brand fans can share their enthusiasm about the brand on these dedicated pages and be united by their common interest in the brand (De Vries et al., 2012). Brand fan pages reflect part of the customers' relationship with the brand, broaden the brandcustomer relationship, and provide a source of information and social benefits to the members (Bagozzi and Dholakia 2002). On these brand fan pages, companies can create brand posts containing anecdotes, photos, videos, or other material; the brand's fans can then interact with these brand posts by liking or commenting on them.

In this article, this study focuses on the determinants of individuals' involvement with these fan pages by using the brand posts' popularity factors, i.e., the interactivity, informational content, and valence of comment (De Vries et al., 2012). Previous studies found the determinants affecting the brand posts' popularity by conducting research into the effectiveness of the brand posts (De Vries et al., 2012). Similarly, brand posts occupy only a small part of these brand fan pages, with companies wanting the brand's fans to like or comment on them. Thus, the challenges of brand posts are firstly to attract people's attention and secondly to induce people to click on and view the content.

\section{Effect of Social Influence Factors on the Intention to Become Involved with Fan Pages}

Social influence occurs when individuals' thoughts and actions are consciously or unconsciously influenced by others as a result of changes in their perception of other influencers or society (Kelman, 1961). The social influence theory describes two forms of the social influence processes, namely internalization and identification.

Internalization is the process of the formation of the perceptual suitability of values between individuals and other people or the community. Social influence will effectively form in a person when that individual is susceptible to agree with the attitudes of other people or the community. Individuals with internalization would voluntarily behave and consciously act with regard to something which they consider appropriate to their intrinsic value systems.

Individuals who perceive conformity among their intrinsic values and online communities will be motivated to get involved in the communities. Malhotra and Galletta (1999) found internalization predicted the intention to become involved in online communities. Internalization also predicted an intention to become involved in SNS, the intention to be involved in online brand communities (Bagozzi et al., 2002) and attitude preferences towards online advertising (Bagozzi et al., 2006).

This study argues that individuals who receive social influences from fan pages, and perceive conformity between the values and goals of these fan pages and their own intrinsic values and goals, will have the intention to involve themselves with fan pages. Based on these explanations, the first hypothesis developed by this study is as follows:

H1a: Internalization positively affects individuals' intentions to involve themselves with fan pages.

The second dimension of the social influence theory is identification, the formation process of an individual's perception to behave in accordance with the values espoused by certain people and the communities or society he or she admires. Identification shapes individuals' attitudes and behaviors to conform to community standards. Social influence will effectively form when an individual's attitude and behavior conforms with the attitude and behavior of 
someone he/she admires or respects, such as the elderly or celebrities. Individuals with identification would voluntarily behave and consciously act in response to something which they consider congruent with their intrinsic values. However, identification can be mandatory when the individual's decision is motivated by the need to satisfy others or to maintain the relationship or social identity with the community.

Identification is a strong predictor of the extrinsic motivation of individuals to participate in SNS (Bagozzi et al., 2002). Individuals who perceive the attractions of a community, will be motivated to get involved with that community. Malhotra and Galletta (1999) found that identification predicted an individual's intention to be involved in online communities and online advertising (Bagozzi et al., 2006).

This study argues that individuals who receive fan pages' social influence and also perceive the attractiveness of fan pages will maintain their relationship with others and gain a social identity from the fan pages, which will encourage them to further engage with the fan pages. Based on these explanations, the second hypothesis developed in this study is as follows:

H1b: Identification positively affects the individual's intention to be involved with fan pages.

\section{Effect of Interactivity on the Intention to be Involved with Fan Pages}

Interactivity is defined as the level of interparty involvement with communications, communication media, messages, and the degree of influence syncronization (Liu and Shrum, 2002). Interactivity is characterized by the twoway communications between companies and customers or among customers, which is differently characterizing the communication of many parties (Goldfarb and Tucker, 2011). Fan pages' characteristics differ in their degree of interactivity. For example, a text shaping fan page is simply less interactive than a website link (Fortin and Dholakia, 2005).

Previous studies show different findings for the effect interactivity has on attitudes toward advertising (Liu and Shrum, 2002). Some research suggests the possibility of an optimal level of interactivity (Fortin et al., 2005), but other studies have suggested a linear effect of interactivity (Coyle and Thorson, 2001). Because the purpose of fan pages is to motivate the fans' reactions to the brand (ie, liking and/or commenting), then a higher degree of interactivity will encourage individuals to become involved with the fan pages, by giving likes and comments. Thus, the third hypothesis proposed by this study is as follows:

$\mathrm{H} 2 \mathrm{a}$. The higher that the interactivity of the fan pages is, then the higher the individual's intention to be involved with the fan pages will be.

\section{Effect of the Informational Content on the Intention to be Involved with Fan Pages}

Searching for information is the main reason for people to use social networking sites (Liao et al., 2011) and to participate in virtual communities (Bagozzi et al., 2006). Information searches explain the reason people consume a certain brand's content (Muntinga et al., 2011). Therefore, if the brand's posts contain information about the brand or product, then the motivation of the brand's fans to participate or consume the content are fulfilled. Previous studies show that humans tend to have a positive attitude towards informative advertising on social networks (Taylor et al., 2011). Therefore, fans of a brand may have a more positive attitude toward informative brand postings than noninformative ones, thus leading to the intention to be involved with its fan pages. Thus, the fourth hypothesis proposed by this study is as follows:

$\mathrm{H} 2 \mathrm{~b}$. The more informative the fan page is, the higher is the individual's intention to become involved with the fan page.

\section{Effect of the Valence of Comment on the Intention to be Involved with Fan Pages}

The valence of comments is the desire of the brand's fans to make positive, neutral, or negative comments on a fan page (De Vries et al., 2012). Previous research has shown that 
online consumer discussions about their positive experiences with the product or brand generated empathy and positive feelings among the members (Bickart and Schindler, 2001). The exchange of information and experiences among consumer had a positive effect on the perceived value of a product, and the likelihood of the product being recommend (Gruen et al., 2006) and purchased (Chintagunta et al., 2010). Positive comments on a fan page have values that complement the company's brand posts (Bronner and de Hoog, 2010), and thereby increase the attractiveness of the fan page. Additionally, positive comments from fans of the brand can increase the value of the brand and create empathy among the brand's fans. This study argues that positive comments on fan pages will encourage other members to involve themselves with a fan page. Thus, the fifth hypothesis proposed by this study is as follows:

H2c. Positive comments on fan pages positively affect the intention to become involved with fan pages.

\section{The Effect of Intention on the Involvement with Fan Pages}

According to Bagozzi and Dholakia (2002), there are three levels of explanation for the decision making in social research: (1) Classical individual based models (a personal intention to perform an individual act by oneself), (2) contingency consistency and other normative based models (a personal intention to perform an individual act but with consideration of the social influence), and (3) a group-based model (the model comprises of both personal intention and social intention to perform a group act). Two important concepts arise with this classification, I-intentions (classical individual-based models) and we-intentions (group-based models).

In the past two decades of Information Systems (IS) research, the predominant focus has been on the classical individual based models (Bagozzi and Dholakia, 2006). The intention to use (I-intention) a new technology depended on an individual's reasons and the perceived social pressures for using the new technology. This approach was particularly useful to the previous studies, as the focus had been predominantly into standalone information systems. Decision makers were more likely to form an intention, or to act in concert with their attitudes, insofar as the perceived norms encouraged making such a decision. Web 2.0 created a new world of collaboration. People came together to create, collaborate, and contribute their expertise and wisdom. They supported themselves and each other through their comments, discussions, and instant messages. Unlike the traditional individualbased approach (personal intention to perform an individual act), social interaction and connection has been the objective with Web 2.0 technologies, including online social networks. Associated with these new phenomena in human communications and interaction patterns, the we-intention, which has encapsulated social behaviors by its collectivity, is a more appropriate approach to study users' participation in online social networks.

However, online marketing studies still used intention (the I-intention) to predict behavior. Bagozzi and Dholakia (2002) stated that intention gave encouragement to being involved or re-involved with online communities. Studies conducted by Bagozzi and Dholakia (2006) found a positive effect of intention on an individual's involvement with online brand communities. Their studies also found an indifference to the intention to be involved or reinvolved with online communities. Therefore, this study also used intention (I-intention) and argued that the intention to involve or re-involve with fan pages was shaped by social influences and the determinants of involvement with SNS will encourage individuals to get involved with the fan pages. Thus, the sixth hypothesis developed in this study is as follows:

H3: The intention to be involved with fan pages has a positive effect on the individual's involvement with fan pages.

Figure 1. illustrates the empirical model of an individual's involvement with fan pages. 


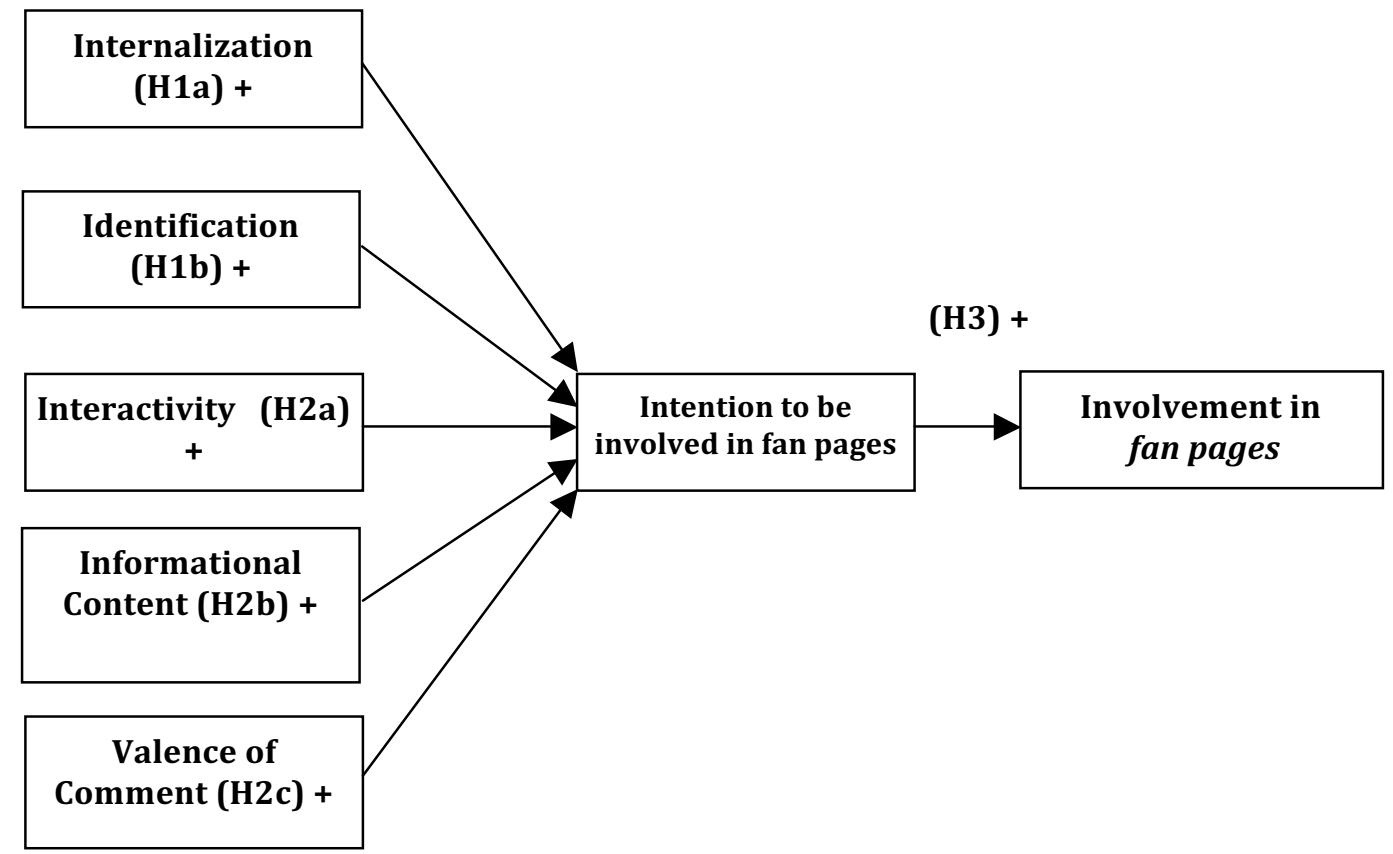

Figure 1. Empirical Model of Individual's Involvement with Fan Pages

\section{RESEARCH METHOD}

This research is a confirmatory study that aims to answer the research questions and hypotheses (Cooper and Schindler, 2006) with a quantitative approach. The design used was a survey employing a questionnaire.

The measurement of internalization used three items adapted from Malhotra and Galletta (1999), namely: The availability of fan pages, the shared personal values with the fan pages, and personal interests. The measurement of identification used three items from Malhotra and Galletta (1999), namely: The proud statement, revealing to others, and the self-defining of fan pages. The measurements of interactivity used ten items from the three sub-dimensions of the interactivity constructs adapted from Liu and Shrum (2002), which were: The active control, two-way communication, and synchronicity. The measurement of informational content used three items which were adapted from Taylor et al. (2011), namely: Information is useful, it is easy to get the information, and the latest information. The measurement of the valence comments used three items adapted from Bickart and Schindler (2001), namely: Comments on the fan pages have high credibility, provide relevant information, and are able to generate empathy. The measurements of intention used three items adapted from Bagozzi and Dholakia (2006), namely: The intention to participate in the fan pages, an intention to participate in the fan pages while clearly describing myself, and a desire to participate in the fan pages. The measurement constructs used a five-response Likert scale, 1 for strongly disagree and 5 for strongly agree. Meanwhile, the measurement of behavioral involvement with fan pages used two items adapted from De Vries et al. (2012), namely: The number of likes and the number of comments on the fan page.

The population in this study was Facebook members who had been involved with a fan page. The sampling procedure was non-probability with a purposive sampling technique. The criteria used to select the sample were: (1) The subjects or respondents were Facebook members who had been involved with a fan page over the past year, to get an overview of the respondents' experiences of their involvement, and (2) the type of fan pages were political campaigns, product advertising, or government pages.

This study collected data from a sample of respondents using online questionnaire survey techniques. Researchers sent online questionnaires to all the members of the community 
through the sites' pages https://docs.google. com/forms/d/16d80u_IlJDgih_J_V7P116z5HuCjmgPrIpZ27dC_E8/viewform?c $=0$ andw $=1$ andusp $=$ mail_form_link. In order to maximize the response rate, the researcher also designed pre-alert notices, such as an initial announcement to all the respondents via e-mail before the questionnaire was sent out; an electronic cover letter to be attached to the questionnaire to make the respondents feel appreciated, the returns were to be anonymous and finally a reminder e-mail.

\section{ANALYSIS AND DISCUSSION}

This research is a confirmatory study of fan page users in Indonesia. This study uses survey design. Of the 300 questionnaires distributed online during February through personalized emails and the mailing list of the respondents, all 300 of the questionnaires were returned, giving a response rate of 100 percent, and all of them were fit for use in our analysis. Table 1 presents a description of the characteristics of the study sample.

The description of the sample's characteristics provides an overview of the gender, age, occupation, marital status, type of fan pages visited, length of membership of the pages, and the number of likes and comments. Based on this description, there is no missing value in the sample, except for the number of comments but the percentage of the missing value is very small compared to the total data. Thus, statistically, this condition does not affect the total data analysis overall.

By sex, most of the respondents are men, so that the general findings of this study represent a group of respondents which, in cognitive psychology, is a group of people who tend to think more rationally. Therefore, the majority of the group is expected to represent research that examines the cognitive aspect, such as the perception of their motivation for their involvement with fan pages.

In terms of age, the average respondent is 27 years old (rounding down from 27.24). This age group is considered as adult in its capacity for thinking and acting, so that this group is expected to represent the research. Meanwhile, the majority of the respondents classed their occupation as employees. This productive, working, age group is expected to be relevant and to present sensible measurements of their rational motivation for their individual involvement with fan pages, because this group is one of the active user groups of online social media.

Based on their marital status, the majority of the respondents have not yet been married. Although previous empirical studies have not reviewed the relationship between marital status and involvement with fan pages or online social media, this study logically assumes that one's marital status indirectly shapes their maturity of thought, which would be more likely to be formed when the individual has married, so the learning process about the complexities and responsibilities of adult life starts. Thus, the majority of respondents, since they have not been married, which presumably would indirectly affect their individual intentions to be involved with fan pages, because of the tendency for motivational involvement, which is not based on conscientiousness.

Table 1. Characteristics of the Sample

\begin{tabular}{lllllllll}
\hline & Gender & Age & Occupation & Status & $\begin{array}{c}\text { Type of } \\
\text { fan page }\end{array}$ & $\begin{array}{c}\text { Length of } \\
\text { Membership }\end{array}$ & Like & Comment \\
\hline N Valid & 300 & 300 & 300 & 300 & 300 & 300 & 300 & 298 \\
$\quad$ Missing & 0 & 0 & 0 & 0 & 0 & 0 & 0 & 2 \\
Mean & 1.40 & 27.24 & 2.05 & 1.29 & 2.00 & 2.25 & 3.70 & 1.47 \\
Mode & 1 & 25 & 2 & 1 & 1 & 3 & 4 & 1 \\
Skewness & 0.41 & 1.41 & 0.34 & 0.91 & 0.75 & -0.47 & -0.87 & 0.98 \\
Std. Error of Skewness & 0.14 & 0.14 & 0.14 & 0.14 & 0.14 & 0.14 & 0.14 & 0.14 \\
\hline
\end{tabular}

Source: Data processed (2015) 
Based on the types of fan pages, this study found that the most widely followed types of fan pages are those featuring product advertising. This indicates that the online social media, such as Facebook, are filled and used as a communications arena for product marketing. This leads the analysis and discussions of this study to the motivation for an individual's involvement in product advertising fan pages. However, further analysis and discussion are still required for other types of fan pages.

Based on the length of time the respondents stated they have followed certain fan pages, this study found the average length of time was 2 years. This finding indicates the existence of sufficient experience in the respondents involved with fan pages. It also indicates the relevance of the careful selection of the sample in order to fulfill the research's objectives.

Based on the number of likes and comments given by the respondents to the fan pages, this study found the average number of likes to be approximately 4, and the average number of comments was 1 . This finding indicates the existence of a certain level of respondents' activity to the fan pages. It also indicates that the tendency to give a like is easier than to make a comment. Thus, this finding implicitly indicates that the motivation for individuals to involve themselves with fan pages (internalization, identification, interactivity, content information, and valence comments) will tend to encourage them to get more involved by giving likes rather than comments.

Based on the outcome of the PLS measurement model in Table 2, the empirical model tested in this research has fulfilled the criteria of the validity and reliability tests.

This study examined two main hypotheses, i.e. the antecedents of the individual's intention to be involved (social influence factors and characteristics of fan pages), as well as the effect of the intention to be involved with fan pages on the individual's actual involvement with fan pages. Hypothesis testing using the Partial Least Square methods were evaluated through the parameter significance of the t-statistic. Table 3 presents the results of the hypothesis testing using the Partial Least Square techniques.

Based on the results of the hypotheses testing, it can be concluded that all of the hypotheses were statistically significant, except hypothesis $1 \mathrm{a}$, which was not supported (internalization does positively affect the individual's intention to be involved with fan pages). Overall, the results were able to explain the antecedents of an individual's involvement with fan pages.

Table 2. Test Outcome of Partial Least Square (PLS) Method of Measurement Model

\begin{tabular}{|c|c|c|c|c|c|}
\hline & AVE* & $\begin{array}{c}\text { Composite } \\
\text { Reliability** }\end{array}$ & R Square & $\begin{array}{c}\text { Cronbach's } \\
\text { Alpha** }\end{array}$ & Communality* \\
\hline Internalization & 0.56 & 0.79 & & 0.62 & 0.56 \\
\hline Identification & 0.79 & 0.92 & & 0.86 & 0.79 \\
\hline Informational content & 0.75 & 0.90 & & 0.83 & 0.75 \\
\hline Interactivity & 0.41 & 0.87 & & 0.84 & 0.41 \\
\hline Valence of comments & 0.71 & 0.88 & & 0.80 & 0.71 \\
\hline Intention & 0.78 & 0.91 & 0.60 & 0.86 & 0.78 \\
\hline Involvement & 0.46 & 0.66 & 0.08 & 0.48 & 0.46 \\
\hline
\end{tabular}

Source: Data processed (2015).

Note: $\quad *$ Valid if AVE and or Communality $>0.5$

**Reliabel if Composite Reliability or Cronbach's alpha $>0.6$. 
Table 3. Test Results of the Partial Least Square (PLS) Method of the Structural Model

\begin{tabular}{lcccccl}
\hline & $\begin{array}{c}\text { Original } \\
\text { Sample } \\
(\mathrm{O})\end{array}$ & $\begin{array}{c}\text { Sample } \\
\text { Mean (M) }\end{array}$ & $\begin{array}{c}\text { Standard } \\
\text { Deviation } \\
(\text { STDEV) }\end{array}$ & $\begin{array}{c}\text { Standard } \\
\text { Error } \\
(\text { STERR) }\end{array}$ & $\begin{array}{c}\text { T Statistics } \\
(\mid \mathrm{O} / \text { STERR } \mid)\end{array}$ & Note \\
\hline Identification -> Intention & 0.35 & 0.35 & 0.08 & 0.08 & 4.39 & Supported \\
Informational content -> Intention & 0.09 & 0.08 & 0.08 & 0.08 & 1.97 & Supported \\
Intention -> Involvement & 0.29 & 0.31 & 0.07 & 0.07 & 4.19 & Supported \\
Interactivity -> Intention & 0.14 & 0.15 & 0.09 & 0.09 & 1.97 & Supported \\
Internalization -> Intention & 0.15 & 0.15 & 0.08 & 0.08 & 1.57 & Rejected \\
Valence of comments -> Intention & 0.27 & 0.27 & 0.08 & 0.08 & 3.38 & Supported \\
\hline
\end{tabular}

Source: Data processed (2015).

This study examines an empirical model of an individual's involvement with fan pages. This study is important because practically, the growth of online social media, especially fan pages, has opened new marketing communications methods for the companies with their customers. It has also encouraged the emergence of urgent empirical studies evaluating the motivation for individuals' involvement with fan pages, because the online brand popularity model can be developed by integrating it with the social influence theory. This integration is expected to provide better theoretical explanations than the previous studies.

This study used a survey design with an online questionnaire as the data collection method. The study included individuals with diverse genders, ages, marital status, occupations, types of fan pages, and number of likes and comments. In general, this study found that not only the fan pages' characteristics (interactivity, content information, and valence comments) but also the social influences factor encouraged individuals to become involved with fan pages. However, this study only found the extrinsic motivation, which was identified as a predictor of individuals' intentions to be involved with fan pages. These findings indicated that fan page members in Indonesia tended to become involved because they were driven by an extrinsic motivation in the form of their interest in the fan pages' features, such as the call a friend or colleague feature, or because of an attractiveness agent (such as a public figure), and they had reasons to avoid the social sanctions or socio-economic benefits of their involvement with such fan pages. The following detailed discuss the results of this study.

The first analysis, of hypothesis 1a, which stated that internalization positively affects the individual's intention to be involved with fan pages. But, this study found that internalization has no positive effect on the intention to get involved with fan pages. It means that hypothesis 1a was not statistically supported. This finding is not consistent with the opinion of Kelman's (1953) social influence theory which states that when individuals receive social influences, in the form of messages about the similarity of values which are believed to influence social values, then people will receive social influences publicly or privately. In other words, the individual will be motivated intrinsically, committed, willing and will behave in accordance with the encouragement of the social influence. This finding is also inconsistent with the study by Abdillah et al. (2012) which showed the positive effect of the internalization of the intentions of individuals for involvement with social networking sites.

Internalization is a social influence factor which exhibits the nature of effect as an intrinsic motivation for individuals to involve themselves or behave in certain ways. The internalized people tend to tend act constantly in long term. The result indicates that the individual's involvement with fan pages is not driven by intrinsic motivations or full consciousness. This can be seen by the fact that the frequency and intensity of the individuals' involvement with fan pages are quite rare and the absence of similarity of fan pages' values with personal values. 
The second analysis, of hypothesis $1 \mathrm{~b}$, which stated that identification positively influences the individuals' intention to be involved with fan pages. This study found that identification did positively influence the intention to be involved with fan pages. It means that hypothesis $1 \mathrm{~b}$ was statistically supported. This finding is consistent with the opinion of Kelman (1953) which stated that when individuals received social influences in the form of messages from respected or admired agents, such as celebrities, friends, family members or colleagues, then the individual would receive a general social influence. In other words, the individual would be extrinsically motivated, committed, eager, and would behave in accordance with the encouragement of the accepted social influences. This finding is also consistent with Abdillah et al. (2012) which showed the positive influence of identification on the intention to get involved in social networking sites.

Identification is a social influence factor that indicates the nature of the social influence as an extrinsic motivation for individual involvement or behavior in certain ways. The individual with Identification's social influence tends to behave in the short term. This result indicates that the respondents' involvement with fan pages were reflecting extrinsic motivations, in the form of their interest in the fan pages' features and the agents' appeals.

The third analysis, of hypothesis $2 \mathrm{a}$, which stated that interactivity had a positive effect on the individuals' intentions to be involved with fan pages. This study found that interactivity had a positive effect on the intention to be involved with fan pages. It meant that hypothesis $2 a$ was statistically supported. This finding is consistent with the study by De Vries et al. (2012). Interactivity is defined as the level of inter-party involvement in the communication media, and marked by two-way communications. Fan pages' characteristics have differences degree of interactivity, such as by being text-based or a link to a website. Various degrees of interactivity are used to encourage individuals to get involved with fan pages. This study also found that a higher degree of interactivity will encourage individuals to be more involved with fan pages by giving more likes and comments.

The fourth analysis, of hypothesis $2 b$, which stated that information content had a positive effect on the individuals' intentions to be involved with fan pages. This study found that information content did have a positive effect on the intention to get involved with fan pages. It meant that hypothesis $2 b$ was statistically supported. This finding is consistent with De Vries et al. (2012). The information content describes the ability of a fan page to provide information that acts as an important reason for people to use social networking sites (Liao et al., 2011), to participate in virtual communities (Dholakia et al., 2004), to contribute to Facebook (Park et al., 2009), and consume content about related brands (Muntinga et al., 2011). Therefore, based on the findings of the research, the study concluded that individuals would have more positive attitudes towards informative fan pages, as compared to noninformative ones. The practical implication of this finding is that online marketers and developers should build and offer informative fan pages in order to reach higher levels of individuals' interest in becoming involved with the fan pages.

The fifth analysis, of hypothesis $2 \mathrm{c}$, which stated that the valence of comments had a positive effect on the individuals' intentions to be involved with fan pages. This study found that the valence of comments did have a positive effect on the intention to get involved with fan pages. It meant that hypothesis $2 \mathrm{c}$ was statistically supported. This finding is also consistent with the study by De Vries et al. (2012). The valence of comments showed that a positive experience of the product or brand can generate empathy and positive feelings among the members (Bickart et al., 2001) which are then exchanged via fan pages. Information and experience exchanges among consumers have a positive effect on the perceived value of a product, and the likelihood of the product being recommend by them (Gruen et al., 2006) and 
also purchased (Chintagunta et al., 2010; Mayzlin et al, 2006). Positive comments from a brand's fans can also increase the value of the brand and create empathy among the brand's fans. This study found that the higher the valence of comments was on fan pages, the more likely it was that the fan pages would encourage individuals to get involved. Practical implications of this finding is that online marketers and the developers of fan pages should stimulate the emergence of the valence of comments from their fan pages' members, so they would attract potential new members to get involved in the existing fan pages.

Based on the detailed description of the entire results of this study, it can be concluded that the empirical model of the individuals' involvement with fan pages may explain the motivation for an individual's involvement with these fan pages. The development of a research model by integrating the social influence theory and the online brand popularity model has provided a scientific explanation for individuals' involvement with fan pages.

Practically, the findings indicate that identification, as a representation of the effect of the superficial appeal and the characteristics of fan pages, is the driving factor for individuals to involve themselves with fan pages. This superficial interest causes individuals to become involved without any specific intrinsic reasons, but to self-define their social relations. The information content provided by fan pages for users, and the information shared through conversations among fellow community members, indicates that WOM is still an effective way to influence individuals' intentions to become involved with online communities, and particularly with fan pages. Both factors also indicate that the rationality aspect is the main factor affecting the individual's intention to be involved with fan pages. Individuals' assess rationally based on the information they receive, both what is available from the fan pages, or obtained through WOM from among the community's members. A rational intention to become involved with fan pages indicates the need to build fan pages as online social media sources, based on objective information that can communicate, educate, and persuade users.

The practical implications of these research findings for stakeholders is how they can improve their design and management of fan pages so they become healthy and productive communications and educational media platforms by providing content that is both symmetric and objective. The appropriate information content will catalyze the valence of comments from fan page users so fan pages will be an effective communication media through positive WOM strategies, both for online businesses, leaders and political parties, or any other non-profit institutions.

\section{CONCLUSION}

This study examined the antecedents of individuals' involvement with fan pages. The results showed that identification, interactivity, content information, and valence of comments had an effect on individuals' intentions to get involved with fan pages, however, internalization did not. This suggests that theoretically, this study presented the empirical explanation of the relevance of the social influence theory and the online brand popularity model in explaining the phenomenon of individuals' involvement with fan pages. Our empirical examination showed that two concepts were able to explain the motivation for individuals' involvement with fan pages.

Meanwhile, this study had several limitations. Firstly, this study used a purposive sampling technique that needed great care when generalizing the results for the various forms of online social media, other than the fan pages. Although the sampling frame of the fan page members was available, access from its administrator to the sampling frame was difficult to achieve. Finally, the online questionnaire had the potential for a low response rate, which necessitated efforts to improve the response rate, such as by personally and repeatedly contacting the respondents.

Practically, these findings may have implications for stakeholders in the social context, 
such as individual and private or public sector organizations, particularly those with interests in electronic business marketing, fan page developers, as well as business leaders and political parties. For individuals, these results provide information about the importance of improving the aspects of rationality in establishing an intention to become involved with fan pages. Rationality, based on objective and symmetrical information, leads individuals to become more confident and conscious of their involvement with fan pages.

In the organizational context, these findings provide critical information for organizations in their planning for online marketing communications' strategies. This study suggests that the information content and positive WOM communications via fan pages can effectively encourage individuals to get involved with fan pages. For electronic business marketers and fan page developers, this study provides important information for designing a marketing communications' strategy and Customer Relationship Management (CRM). If electronic business marketers and fan page developers seek longterm relationships with their customers, the business players and fan page developers need to emphasize the aspects of rationality based on objective and symmetric information in developing and using their fan pages as marketing communications media. This can be fulfilled by providing relevant, productive and informative content for their users, containing aspects of knowledge, learning, and entertainment.

For public figures and political parties, fan pages have now become an important part of Public Relations (PR) strategies to build the popularity of candidates and establish long-term relationships with constituents. These findings can be important information for public figures and parties, since fan page users, who are potential constituents (voters) are now rational users who base their decisions on the information provided, so that the means to effectively entice potential constituents (voters) no longer simply relies on emotional aspects, such as fanaticism. Constituents are now increasingly critical and rational, and should be provided with informative, educational fan pages, which stimulate them to communicate with each other so that the valence of comments is an effective way of marketing communications through positive WOM.

\section{REFERENCES}

Abdillah, W., Jogiyanto, H., and Handoko, H. 2012. Motivation and consequence of individual's involvement in social network sites: A study of social computing of inter collectivist-individualist culture value. Journal of Indonesian Economy and Business, 27(2), 242-272.

Bagozzi, R. P., and Dholakia, U. M. 2002. Intentional social action in virtual communities. Journal of Interactive Marketing, 16(2): 2-21.

Bagozzi, R. P., and Dholakia, U. M. 2006. Antecedents and purchase consequences of customer participation in small group brand communities. International Journal of Research in Marketing, 23(1): 45-61.

Bickart, B., and Schindler, R. M. 2001. Internet forums as influential sources of consumer information. Journal of Interactive Marketing, 15(3): 31-40.

Bronner, F., and de Hoog, R. 2010. Consumergenerated versus marketer-generated websites in consumer decision making. International Journal of Market Research, 52(2): 231-248.

Buttle, F. A. 1998. Word of mouth: Understanding and managing referral marketing. Journal of strategic marketing, 6(3): 241254.

Chintagunta, P. K., Gopinath, S., and Venkataraman, S. 2010. Online word-of-mouth effects on the offline sales of sequentially released new products: An application to the movie market. Marketing Science, 29(5): 944-957.

Cooper, D. R., and Schindler, P. S. 2006. Business research methods (ed.): McGrawHill.

Coyle, J. R., and Thorson, E. 2001. The effects of progressive levels of interactivity and vividness in web marketing sites. Journal of advertising, 30(3): 65-77. 
De Vries, L., Gensler, S., and Leeflang, P. S. H. 2012. Popularity of brand posts on brand fan pages: An investigation of the effects of social media marketing. Journal of Interactive Marketing, 26(2): 83-91.

Dholakia, U. M., Bagozzi, R. P., and Pearo, L. K. 2004. A social influence model of consumer participation in network and small group-based virtual communities. International Journal of Research in Marketing, 21(3): 241-263.

Fishbein, M., and Ajzen, I. 1975. Belief, attitude, intention and behavior: An introduction to theory and research: Addison-Wesley, Boston, MA.

Fortin, D. R., and Dholakia, R. R. 2005. Interactivity and vividness effects on social presence and involvement with a web-based advertisement. Journal of Business Research, 58(3): 387-396.

Godes, D., and Mayzlin, D. 2004. Using online conversations to study word-of-mouth communication. Marketing Science, 23(4): 545-560.

Goldfarb, A., and Tucker, C. 2011. Substitution between offline and online advertising markets. Journal of Competition Law and Economics, 7(1): 37-44.

Gruen, T. W., Osmonbekov, T., and Czaplewski, A. J. 2006. eWOM: The impact of customer-to-customer online know-how exchange on customers' values and loyalty. Journal of Business Research, 59(4): 449456.

Hair, J. F., Anderson, R. E., Tatham, R. L., and Black, W. C. 2006. Multivariate analysis: Prentice-Hall, London.

Hallowell, R. 1996. The relationships of customer satisfaction, customer loyalty, and profitability: An empirical study. International journal of service industry management, 7(4): 27-42.

Hartono, J. 2007. Sistem Informasi Keperilakuan: Penerbit Andi.

Liao, C., Liu, C.-C., Liu, Y.-P., To, P.-L., and Lin, H.-N. 2011. Applying the expectancy disconfirmation and regret theories to online consumer behavior. Cyberpsychology, Behavior, and Social Networking, 14(4): 241-246.
Liu, Y., and Shrum, L. J. 2002. What is interactivity and is it always such a good thing? Implications of definition, person, and situation for the influence of interactivity on advertising effectiveness. Journal of advertising, 31(4): 53-64.

Malhotra, Y., and Galletta, D. F. 1999. Extending the technology acceptance model to account for social influence: Theoretical bases and empirical validation: 14 pp.: IEEE.

Mayzlin, D., Dover, Y., and Chevalier, J. A. 2006. Promotional reviews: An empirical investigation of online review manipulation: National Bureau of Economic Research.

McAlexander, J. H., Schouten, J. W., and Koenig, H. F. 2002. Building brand community. The Journal of Marketing: 3854.

Muniz Jr, A. M., and O'Guinn, T. C. 2001. Brand community. Journal of consumer research, 27(4): 412-432.

Muntinga, D. G., Moorman, M., and Smit, E. G. 2011. Introducing COBRAs. International Journal of Advertising, 30(1): 13-46.

Park, N., Kee, K. F., and Valenzuela, S. n. 2009. Being immersed in social networking environment: Facebook groups, uses and gratifications, and social outcomes. CyberPsychology and Behavior, 12(6): 729733.

Taylor, D. G., Lewin, J. E., and Strutton, D. 2011. Friends, fans, and followers: Do ads work on social networks? Business Faculty Publications.

Trusov, M., Bodapati, A., and Bucklin, R. E. 2009. Determining influential users in internet social networks. Available at SSRN 1479689 .

Van Doorn, J., Lemon, K. N., Mittal, V., Nass, S., Pick, D., Pirner, P., and Verhoef, P. C. 2010. Customer engagement behavior: theoretical foundations and research directions. Journal of Service Research, 13(3): 253-266.

Williamson, A. 2011. Driving CIVIC participation through social media. Paper presented at the European workshop at perspectives of Web.

Zabin, F. 2009. Online Advertisement. Marketing Review: 51. 


\section{APPENDIX}

\section{Item Measurements}

\begin{tabular}{|c|c|}
\hline & Internalization \\
\hline IT1 & The reason I became involved with fan pages is because of what their use stands for \\
\hline IT2 & $\begin{array}{l}1 \text { like being involved with fan pages primarily based on the similarity of my values and what its use } \\
\text { stands for }\end{array}$ \\
\hline \multirow[t]{2}{*}{ IT3 } & What the involvement of a fan page stands for is important for me \\
\hline & Identification \\
\hline ID1 & I am proud to be involved with fan pages \\
\hline ID2 & 1 talk up my involvement with fan pages to my colleagues as having great utility for me \\
\hline \multirow[t]{2}{*}{ ID3 } & 1 feel a sense of "ownership" by my use of a fan page \\
\hline & Interactivity-Active control \\
\hline IC1 & I felt that I had a lot of control over my experiences with this fan page \\
\hline IC2 & While I was on a fan page, I could freely choose what I wanted to see \\
\hline \multirow[t]{2}{*}{ IC3 } & While surfing fan pages, my actions decided the kind of experiences I had \\
\hline & Interactivity-Two-way communication \\
\hline IC4 & Fan pages are effective in gathering visitors' feedback \\
\hline IC5 & Fan pages facilitate two-way communications between the visitors and the site \\
\hline IC6 & Fan pages make me feel they want to listen to their visitors \\
\hline \multirow[t]{2}{*}{ IC7 } & Fan pages give visitors the opportunity to talk back \\
\hline & Interactivity-Synchronicity \\
\hline IC8 & Fan pages processed my inputs very quickly \\
\hline IC9 & Getting information from Fan pages is very fast \\
\hline \multirow[t]{2}{*}{ IC10 } & I was able to obtain the information I wanted without any delay \\
\hline & Information Content \\
\hline IF1 & Fan pages are a valuable source of product/service information \\
\hline IF2 & Fan pages are a convenient source of product/service information \\
\hline \multirow[t]{2}{*}{ IF3 } & Fan pages help keep me up to date \\
\hline & Valences of Comment \\
\hline $\mathrm{VC} 1$ & Comments on fan pages have great credibility \\
\hline $\mathrm{VC} 2$ & Comments on fan pages provide relevant information \\
\hline \multirow[t]{2}{*}{$\mathrm{VC} 3$} & Comments on fan pages are able to generate empathy \\
\hline & Intention \\
\hline IN1 & I intent to participate in fan pages \\
\hline IN2 & My intention for participating in fan pages is to completely describe myself \\
\hline IN3 & I want to participate in fan pages \\
\hline
\end{tabular}

